Article

\title{
Computer-Based Concept Mapping as a Method for Enhancing the Effectiveness of Concept Learning in Technology-Enhanced Learning
}

\author{
Gülsüm Aşıksoy \\ Department of Education and Instructional Technology, Near East University, 99138 Nicosia (Via Mersin \\ 10 Turkey), North Cyprus, Cyprus; gulsum.asiksoy@neu.edu.tr
}

Received: 20 December 2018; Accepted: 12 February 2019; Published: 15 February 2019

\begin{abstract}
Technology enhanced learning is a wide area that covers all uses of digital technology to support learning and teaching activities. The computer-based concept mapping has shown potential in enhancing meaningful learning in education. Concept mapping is an important tool that is used in the field of education to help students in understanding the basic concepts and the relationships between them. This research proposes a computer-based concept mapping (CBCM) environment combined with Google classroom to help students reduce their misconceptions and to improve their problem solving skills. Furthermore, it examines the effect of CBCM on the sustainability of concept learning according to student views. The participants were first-year engineering students. The study was conducted in a physics class, and a true-experimental design was used. The experimental group students learned with the Google classroom combined with computer-based concept mapping (CBCM), while the concept group students learned with Google classroom and the traditional method. Data were collected from a physics concept test, problem solving inventory, and semi-structured interviews. The research results indicated that teaching in the CBCM environment combined with Google Classroom provides meaningful learning by correcting the misconceptions of the students. Moreover, there was a significant increase in the problem solving skills of the experimental group as compared to the control group. According to the students' views, it was determined that CBCM enhances the sustainability of concept learning. The results of this study can help educators and researchers to integrate computer-based concept mapping (CBCM) techniques into Google Classroom.
\end{abstract}

Keywords: concept mapping; misconceptions; sustainability; technology enhanced learning

\section{Introduction}

The deficiencies and inaccuracies that exist in the student's prior knowledge cause them to misconfigure the knowledge in their minds. Concept maps are useful tools in assessing students' prior knowledge, misconceptions, and sustainability of their meaningful learning [1].

The source of the difficulties that the students experience in concept learning can be classified as being related to the individual and the individual's environment. Some reasons that are related to the individual are that they have negative attitude, interest, and motivation towards learning, problems in the students' identification and perception systems, lack of prior knowledge, non-scientific prejudice, and the inability to link new knowledge with prior knowledge [2]. The reasons that are related to the individual environment include weakness of teacher-student interaction, inadequate technology tools, the simplicity of course materials and books, inadequate teaching methods, and lack of knowledge of the teacher regarding students' prior knowledge of the subjects [3]. The misconceptions not only negatively affect students' complete learning, but they also prevent the reasoning skill, which is an important factor in problem solving [4]. Because concepts enable the information to be grouped and 
organized systematically, the relations between the concepts constitute principles and help to solve problems [5]. Students with misconceptions tend to only identify the correct and unknown variables in the science lessons and find answers by placing variables into formulae $[4,6]$.

Concept mapping is the most commonly used technique in teaching concepts and identifying and eliminating the misconceptions in the field of education [7]. Concept mapping is a graphical presentation of the relations between the concepts using link words and in a hierarchical manner [8]. The concept mapping technique that was developed by Novak and Gowin (Figure 1) [9] is supported by Ausubel's meaningful learning theory [10]. Meaningful learning theory claims that, in order for meaningful learning to take place, the learners need to assimilate the new concepts with prior knowledge by associating them into a systematic structure. Concept maps are powerful tools that help in identifying the misconceptions of the students as well as in realizing conceptual change and restructuring the students' knowledge [11].

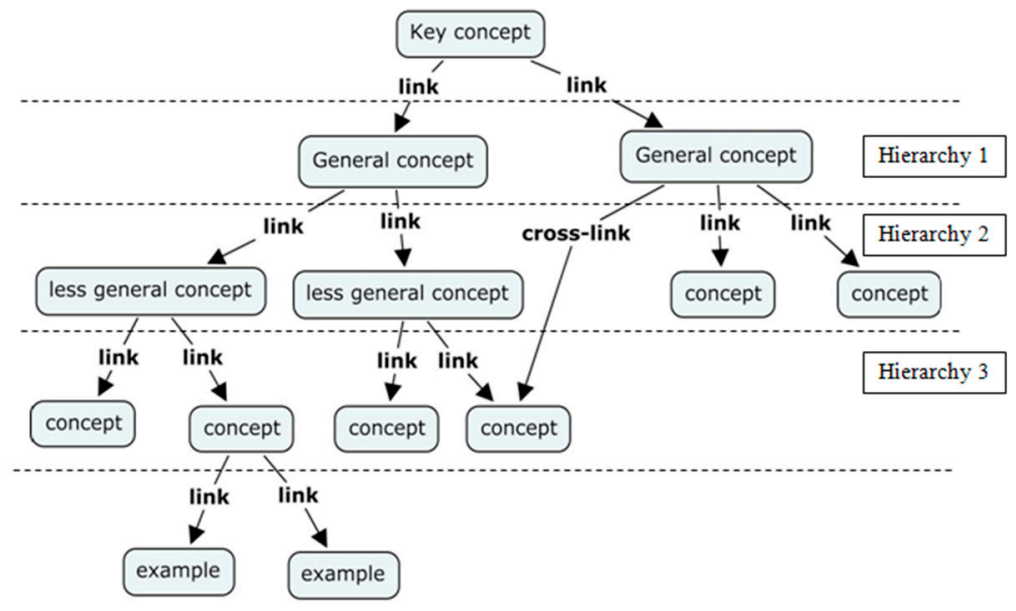

Figure 1. Model of a Concept Map [9].

Quality education is considered to be one of the key elements of sustainable development in the world. As the use of technologies in classroom matures it is necessary in examining how technology-enhanced learning can effectively add to teaching and learning and, consequently, to the imperative of quality education and sustainable growth and development [3]. Technology can be employed to enhance the skills acquisition process, improve critical thinking, engagement, and overall with empowering individuals to seize opportunities and exploit their potential [12]. For efficiently using concept maps in education, technology-based concept mapping systems have been developed [13].

Concept maps can be created on paper or they can be technology based. Some advantages of technology-based concept mapping are: easy restructuring, highlighting, comments, presentability, manipulation, dynamic linking, conversion, and storage [14].

Nevertheless, the use of concept maps is suggested, because they make the students' thinking visible, especially in problem solving processes [15]. Although there are studies that emphasize the benefits of using concept mapping as an assistant tool in the process of concept teaching, there is a limited number of studies that use the computer-based concept mapping as a teaching strategy and that report their impact on the students' problem solving skills [16-18]. However, researchers have identified a critical problem in using concept maps to support learning. This problem creates an extra burden for the teachers when evaluating the concept maps that were developed by the students and it can take a long time for the teachers to give feedback on the concept maps that the students have created. The flow of the education process is prevented by this situation $[19,20]$.

Studies in the literature focused on the impact of computer-based concept mapping on learning performance $[17,20]$. However, there are limited studies on the effect of computer-based concept mapping on students' problem solving skills $[7,17]$. Therefore, this study is to address the insufficiency in the 
literature by providing an empirical study that investigates the possible benefits of computer-based concept maps on students' problem solving skills.

According to Lin et al., computer-based concept mapping provides visualization and interactive features [21]. In this context, Google classroom, which is used as the interface in this study, seems to be a suitable platform for computer-based concept mapping. However, there is no study in which computer-based concept mapping tools have been used in the Google Classroom. Moreover, no studies have used the computer-based concept mapping technique within the Google Classroom platform in relation to physics teaching.

To fill this gap in the literature, the computer-based concept mapping technique was integrated into the Google Classroom, and then the effect on physics teaching was examined. In this context, the impact of combining Google Classroom and computer-based concept mapping (CBCM) on correcting the misconceptions of the students', teaching new concepts correctly and developing their problem solving skills by visualizing their thoughts in the problem solving process have been investigated in this study.

The following research questions were addressed:

- Can a computer-based mapping (CBCM) environment combined with Google Classroom reduce the students' misconceptions?

- Can a computer-based mapping (CBCM) environment combined with Google Classroom improve the students' problem solving skills?

- What are the students' perceptions of the computer-based mapping (CBCM) environment combined with Google Classroom?

\section{Theoretical Background}

\subsection{Concept Mapping}

Novak and Gowin developed concept maps [9], which were in accordance with the theory of meaningful learning. Depending on Ausubel's theory, concept maps are schematics that link the individuals' prior knowledge and new knowledge, and that show how individuals relate concepts in their minds [9]. A concept map is a visual thinking tool that can be applied to all cognitive functions, especially to memory, learning, creativity, and analysis [22]. According to another definition, the concept mapping is a valid approach that helps students to structure and present conceptual information by using their visualization skills to improve their study skills [23].

Concept maps have many intended purposes, such as visualizing information as well as generating, evaluating, and organizing ideas. The concepts, the relationships between the concepts, and propositions are the basic components of the concept map. Two concepts are connected with a connection line and words called "linking words" are written on it, which indicate the relationship between the concepts [9]. The two concepts and the unit that is formed by the linking word that expresses the relations between these concepts is called a "proposition", and it is considered to be the essential component of the concept map [24]. A good concept map should have certain properties, which are that the basic concepts should be arranged hierarchically, the fundamental concepts should be determined, the concepts should be in circles or boxes, propositions that describe the relationships between the concepts should be written, the direction of the arrows in the relations should be determined, and the concept maps and components should be visible and readable [25].

Previous studies have focused on determining student achievement and the effects of the concept maps on the attitudes towards a given course. For example, Dosanjh analysed the effect of the technique of forming three different concept maps (concept determination, proposition determination, and mapping from scratch) on the understanding of the circulatory system of 7 th grade students. As a result of the study, it was concluded that the technique of creating three concept maps was a tool that could increase the students' science achievements [26]. Lin et al. stated in their study that concept maps have a positive effect on students' achievements and their attitudes towards a course [21]. Nakipoglu 
and Ertem compared concept map scores that were obtained from different scoring techniques (structural scoring, relational scoring, and proposition accuracy scoring methods) [27]. Akinoglu and Yasar reached the conclusion in their study that concept maps had a positive effect on students' attitude towards their science course and their academic success [28]. In other previous studies, the effectiveness of concept maps, as an assessment tool, has been analysed $[26,29,30]$. These studies have revealed that the concept mapping has a significant effect on learning, student achievement, and attitudes, and that the concept mappings can be used as an evaluation instrument.

\subsection{Computer-Based Concept Mapping}

Concept mapping that is made with paper and pencil is a complex task. Many students find making concept maps with paper and pencil time consuming and exhausting [31]. Since paper-based concept maps are two dimensional and have limited space, it is difficult to place all the possible relationships between concepts on them [9]. Computer-based concept mappings provide potential benefits for both students and educators by eliminating the limitations of the traditional paper-based concept maps [32,33]. The benefits of computer-based concept mappings are presented below:

- they are user-friendly and corrections can be made more efficiently; the nodes can be quickly added, corrected, or deleted;

- the convenience of communication with peers: Students can obtain precise information by showing the concept maps on the screen to each other and then discussing them;

- they support the active learning strategies of feedback and evaluation and they can present common online tools for map history functions [34].

According to Plotnick, the technique of concept mapping can be easily prepared and the potential benefits are enhanced with the use of computers. There are many advantages of computer-based concept mapping as compared to the paper-based maps, such as the ability to automatically add concept boxes, correct erroneous placements without redrawing, record sound, add video, and link concept maps [35].

There are many platforms for computer-based concept mappings, such as Bubbl.us (https://bubbl. us/), MindMup (http://www.mindmup.com/), FreeMind (http://freemind.sourceforge.net/wiki/ index.php/Main_Page), and Mindomo (https:/ / www.mindomo.com/). These consist of multipurpose programs that enable the integration of digital data (web links, images, videos, articles) into the map [33].

Studies in the literature have generally focused on the comparison between paper-based concept mapping and computer-based concept mapping. For instance, in their study, Liu, Chen, and Chang concluded that computer-based concept mapping improves the ability of the EFL students' understanding of the things that they read in English [36]. Wu et al. analysed the effect of giving feedback through computer-based mapping on the learning performance of nursing students [20]. Hwang, $\mathrm{Wu}$, and Ke used the computer-based concept mapping approach in a natural sciences course in a primary school and they have found that it is beneficial for improving students' learning performance [37]. Chu, Hwang, and Liang proposed a collaborative computer-based concept mapping approach to help with interpreting and organizing the data that were collected in web-based information searching activities. The students' attitude, self-efficacy, and success were demonstratively improved through this approach [38]. Shamsuddin et al. analysed the impact of the computer-assisted concept mapping teaching strategy on student performance in a chemistry course. As a result of the study, it was found that this strategy was gender-friendly because the performance of both male and female students increased at the same rate [39].

\subsection{Problem Solving Skills}

Problem solving skills are the skills of limiting and understanding a problem that is encountered, selecting the appropriate method for the solution, using this method, and then analyzing the results [40]. Problem solving is considered to be an essential cognitive activity in everyday and business life, and it 
is an important survival skill in developed societies. When this skill is acquired, it becomes a routine for an individual to apply a problem solving approach in order to explain the events around them [41].

Thinking is one of the most important activities for problem solving skills. Identifying a problem initiates the thinking activity; the solution of the problem turns into an aim for the individual and then leads him or her to think. Thus, thinking that emerges in relation to a problem creates a process. In this process, it is important to use techniques that enable the individual to think at a higher level [42]. In the field of education, problem solving emerges as a skill that provides personal development and effective learning [43]. Recent studies have revealed the importance of encouraging meaningful learning and the importance of making thinking visible in enhancing problem solving performance $[17,44]$. Hwang et al. argued that the integration of concept mapping in learning would subsequently improve the problem solving skills of the students and their knowledge of the subject [17]. As mentioned, concept mapping in the literature is mainly used in conceptual learning contexts. There are very few studies that have reported the impacts on research or problem solving contexts. For instance, in the study of González et al., it was shown that concept mapping is a tool that has a positive impact on the medical physiology of students' problem solving performance [45]. Sarker has revealed that the use of concept mapping as a tool for solving engineering problems increased the participation of the students and helped in problem solving [46]. Wang et al. identified that the cognitive mapping approach had a promising effect in improving the students' problem solving performance, subject knowledge, and internal motivation for solving complex problems [7]. Hwang et al. found that integrating concept mapping with problem solving based learning can improve students' problem solving performance and subject knowledge [17].

\subsection{Google Classroom}

Google Classroom is a platform that can work with G-mail, Google Docs, and Google Drive to facilitate and accelerate the work of both the teachers and students [47]. Google Classroom has many advantages for both the students and teachers. For instance, with Google Classroom, teachers can automate and organize the distribution and collection of assignments. Teachers can make corrections on homework and provide necessary feedback. Teachers can make quick announcements with Google Classroom and students can help each other because of the ability to share through the class stream [48].

It is not necessary to be a registered user at an educational institution in order to use Google Classroom. Anyone with a Google account can sign up and access all the applications, such as Drive, spreadsheets, docs, slides, etc. The application is easily accessible and applicable in face-to-face learning environments or online environments for educators or learners. It is also easy to use on mobile devices. Mobile access to learning materials that are attractive and easy to interact within today's web-connected learning environments is very important [49].

\section{Methodology}

\subsection{Research Design}

In this study, a pre-test and post-test design with a control group was used. In the first week, each student was randomly assigned to the experimental group or the control group. Additionally, the experimental students' group was given training on how to create a concept map with the MindMup application and then sample applications were performed.

In the second week, the Physics Concept Test (PCT) and the Problem Solving Inventory (PSI) were applied as a pre-test for the students in both groups. At the end of the experimental processes, PCT and PSI were applied as a post-test for both groups. Furthermore, 17 volunteers from the experimental group were individually interviewed for the CBCM environment that was integrated into Google Classroom. The research design is shown in Figure 2. 


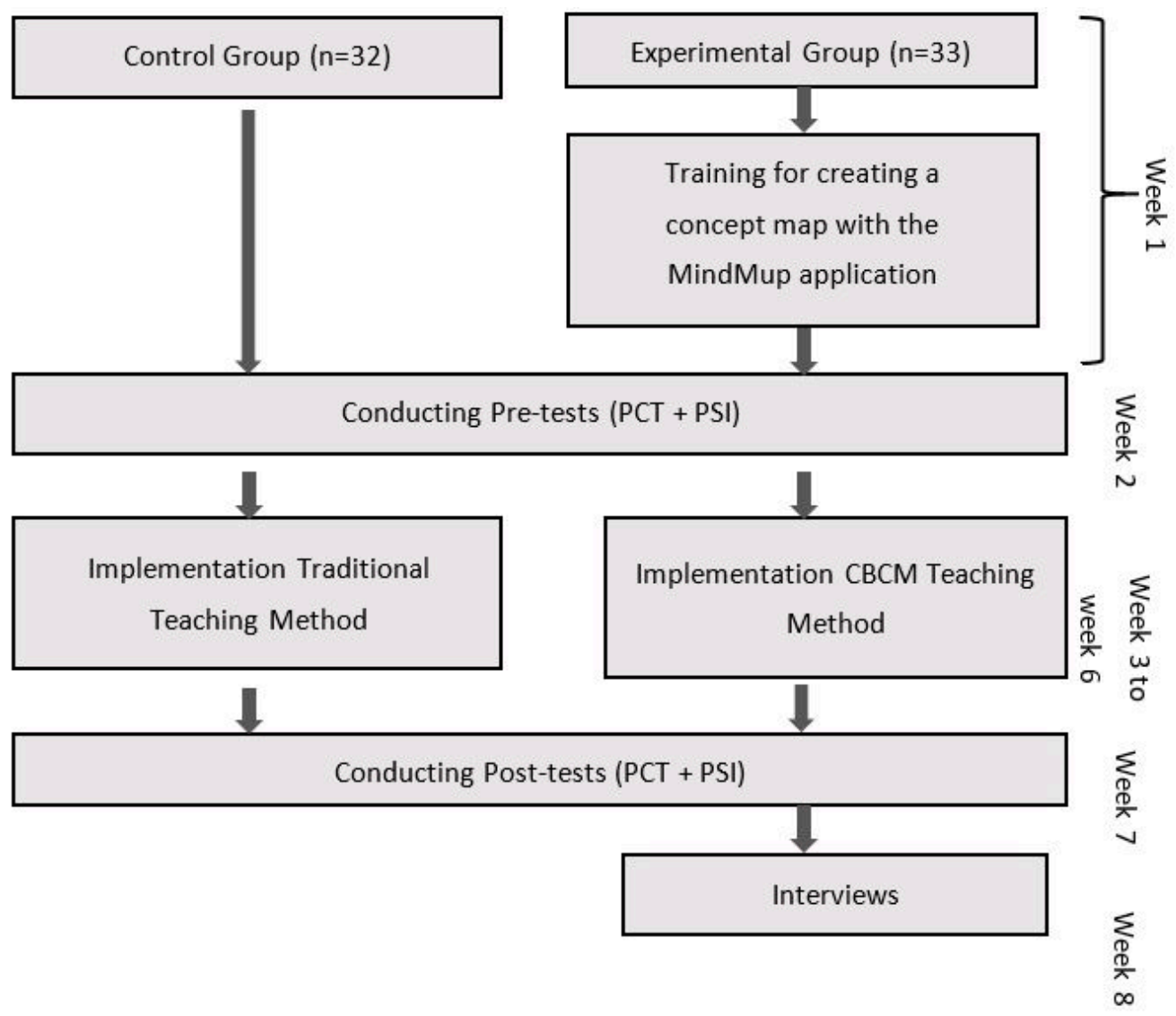

Figure 2. The research design.

\subsection{Participants}

A total of 65 first-year engineering students that enrolled in the physics course at Near East University during the fall semester of the 2017-2018 academic year were included in the study. The students were randomly assigned to the experimental $(n=33)$ and control groups $(n=32)$. The experimental group students consisted of 20 males and 13 females, while the control group consisted of 17 males and 15 females. In the experimental group, the physics courses were conducted in a computer-based concept mapping environment that was integrated into the Google Classroom, while in the control group, the traditional teaching method was applied together with Google Classroom. Both of the groups attended the general physics class twice a week (90 mins per week). The two groups attended the class on different days.

The students in the experimental group had not used the MindMup application before. Since the researcher was an expert in the field of physics, the lessons were carried out by the researcher. Due to the ethical requirements of the research, the names of the students were kept confidential. The students in the experimental group brought their laptops to the class and the MindMup application was installed on each laptop.

\subsection{Concept Mapping Application}

In this study, MindMup (www.mindmup.com), which is a free online concept mapping tool that can be integrated with Google Drive, was used. With the MindMup application, an unlimited number of concept maps can be created and stored, and they can be accessed from a browser or a mobile device independent of time and space. The concept maps can be collaboratively edited, shared, and exported in different formats (e.g., PNG, HTML, FreeMind) with the MindMup application. The application can work on a desktop, tablet, and mobile browsers without any problems. 


\subsection{Experimental Procedure}

The researcher created virtual classes for both the experimental group and the control group for the General Physics-I course in Google Classroom. The virtual class codes that were created were then sent to the students via e-mail. The students used the respective code and then registered to their classes. In the experimental study, the General Physics-I topics that were taught in both groups were the same.

Experimental group: The study design used in the experiment group is presented in Figure 3.

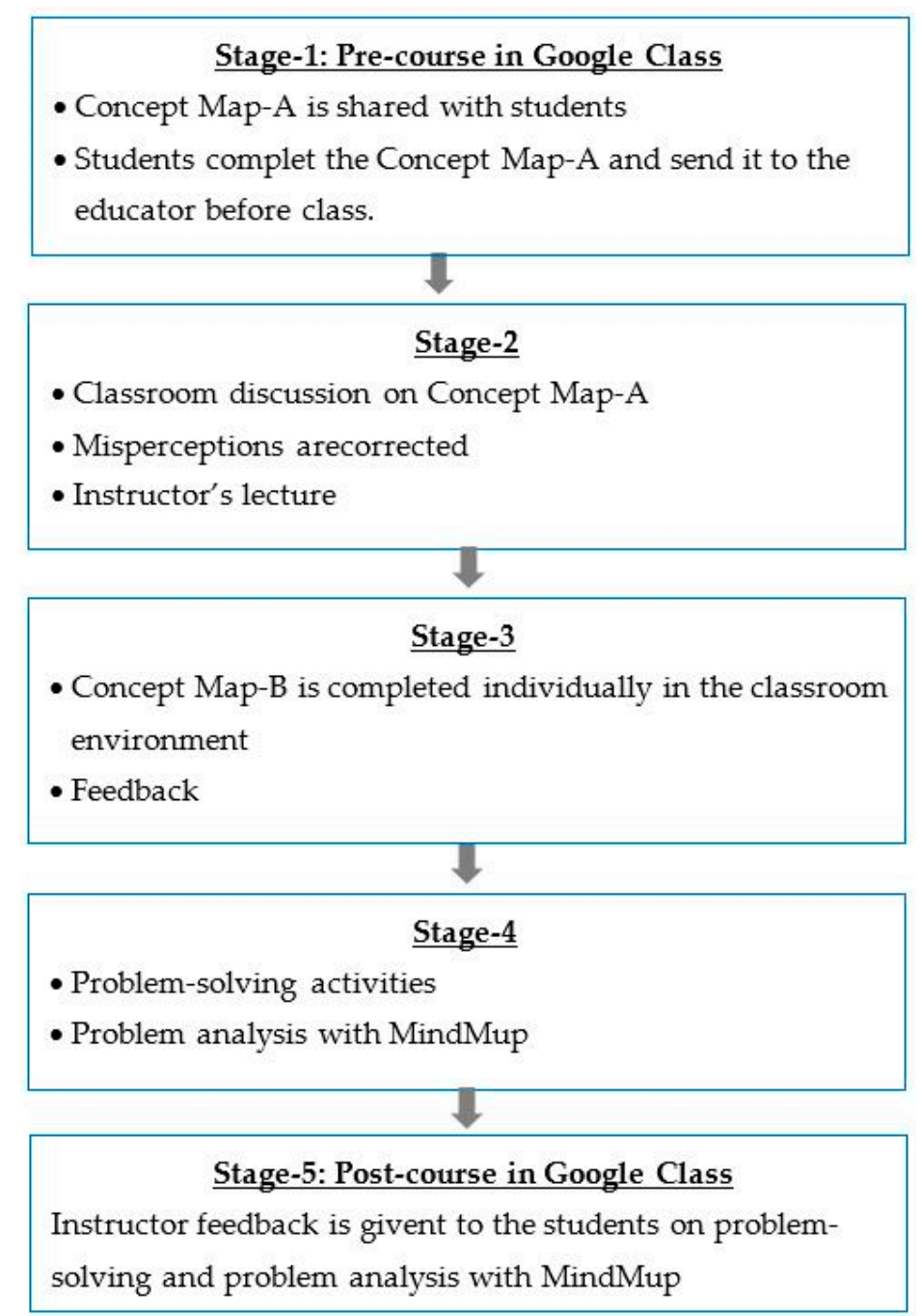

Figure 3. The experiment group study design.

Stage 1. The instructor using the MindMup application prepared a concept map that consisted of concepts within the subject (Concept Map-A). The concepts were placed on this map, but the relationships between the concepts were left blank. A list of relations that included the relations between the concepts was also prepared. The list of relations and Concept Map-A were shared in a Google Classroom that was created for the experimental group (Figure 4). The students individually placed the relations between the concepts on the map and then shared it with the instructor through Google Drive before the class by the submission date that had been determined by the instructor. Thus, the instructor learned about the students' misconceptions and prior knowledge on the subject before the class. 


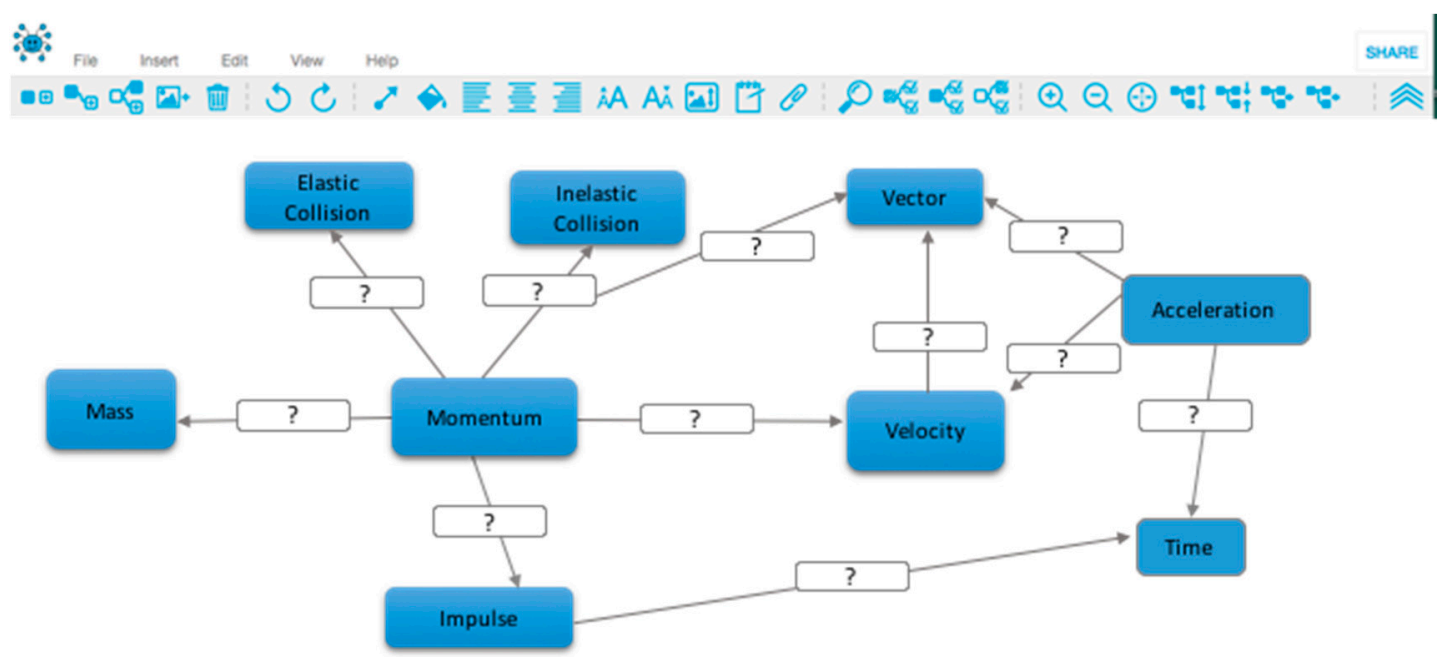

Figure 4. Sample Concept Map-A sent to students and relation list.

Stage 2. During the class hour, a discussion environment was provided in relation to the concept maps (Concept Map-A) that were completed by the students, and the misconceptions that were determined were corrected. Subsequently, the instructor taught the subject.

Stage 3. In this stage, the instructor shared the second map (concept Map-B) in Google Class in which the concepts were left blank and the relations between the subject were placed on the map to be filled in by the students during the class. The instructor also shared the concept list with students in Google Classroom (Figure 5). The students placed the concepts and then sent them to the instructor. The instructor analysed the concept maps through drive and then gave appropriate feedback.

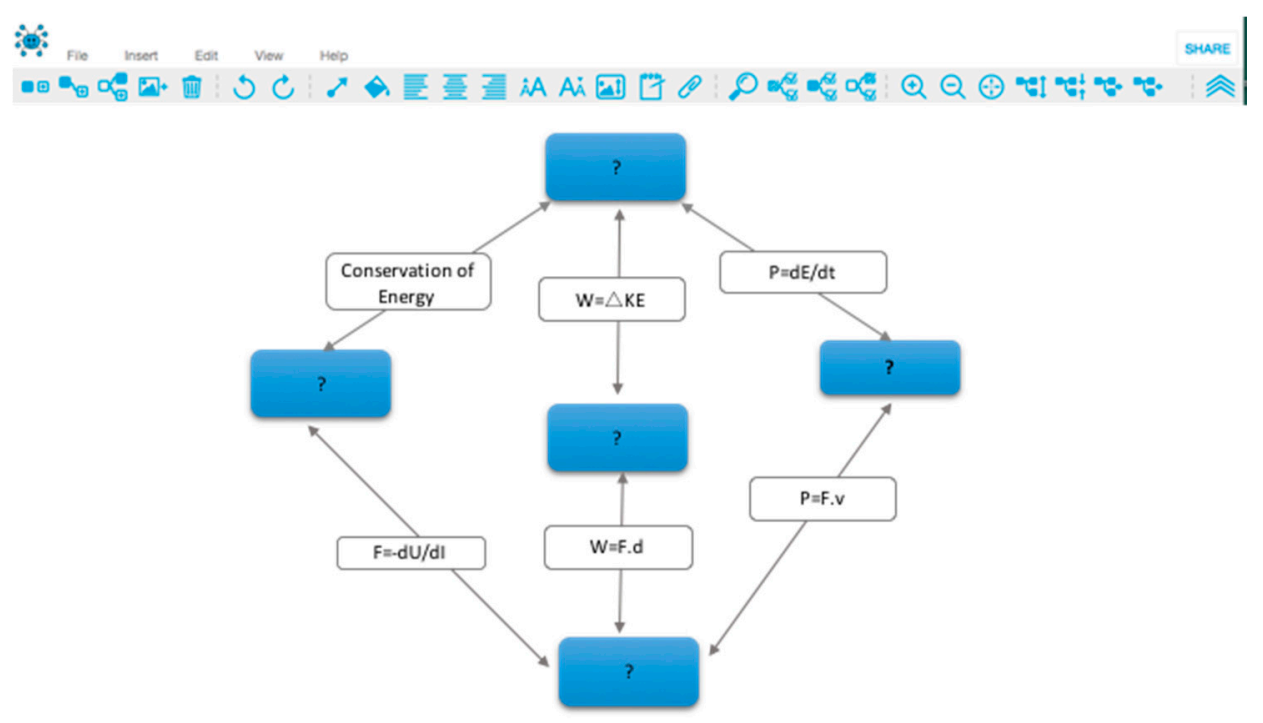

Figure 5. Concept Map-B sample sent to students and concept list.

Stage 4. (The last 30-40 min of the lesson): In the last hour of the lesson, problem solving activities that were related to the subject were carried out. The problem solutions were performed with the MindMup application (Figure 6). Each student shared their solutions to the instructor through Google Classroom.

Stage 5. Within two days, the instructor provided feedback to students individually on their problem solving and analysis of the problem with MindMup. 
Problem: A 1000-kg car traveling north collides with a 2000-kg truck traveling east. The occupants, wearing seat belts, are uninjured, but the two vehicles move away from the impact point as one. The insurance adjuster asks to find the velocity of the wreckage just after impact. What is the answer? [50].

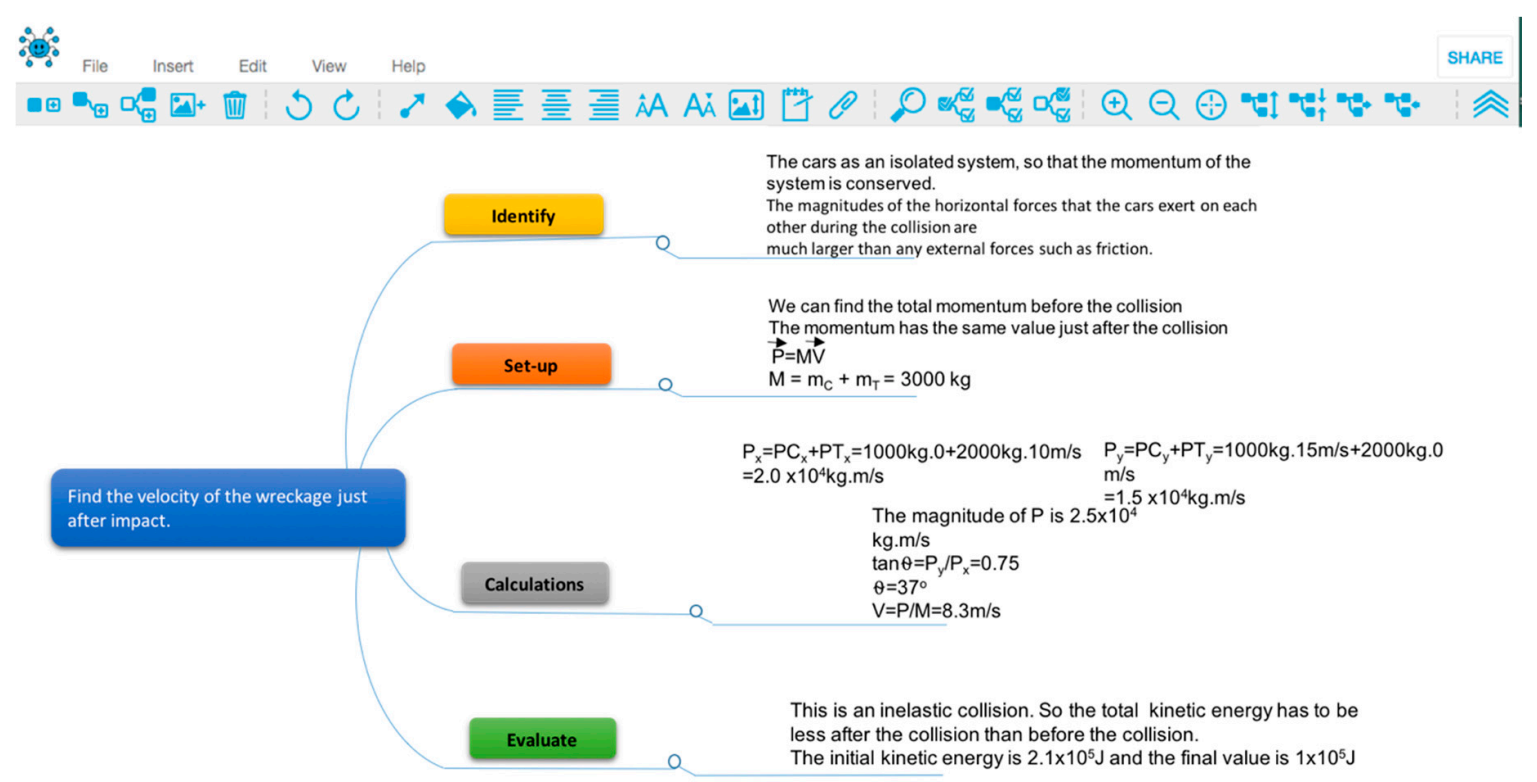

Figure 6. A student problem solving with the MindMup application.

Control group: The instructor sent the list of concepts that were found in Concept Map-A, which was shared with the experimental group of students through the Google Classroom that was created for the control group in order to ensure that the students were aware of the concepts before coming to class. Therefore, it was attempted to make the same pre-class preparation with the experimental and with the control group of students.

The courses in the control group were carried out with the traditional teaching method. Problem solving activities comprised the last 30-min of the course.

Concept maps were not used before class, during lectures, or during the problem solving stages.

\subsection{Data-Collecting Tools}

\subsubsection{Physics Concept Test (PCT)}

The Physics Concept Test (PCT) was developed by the researcher who is an expert in the field in order to determine the misconceptions of the students. The resource books that were used in the General Physics-I course were examined. A PCT consisting of 30 multiple choice questions was prepared on the topics that were going to be taught in the experimental process. There were five options for each question in the PCT, which was consisted of two stages. In the second stage, the students were asked to give a brief explanation of their answers. Therefore, the test can provide reliable and valid results by reducing student guessing. Three faculty members from the field of Physics education examined the PCT in order to ensure content validity. After the examination, making necessary corrections that are in line with the views of the experts validated the test.

A pilot implementation was carried out in order to perform validity and reliability analyses before the actual implementation of the PCT that had been corrected. The pilot implementation was carried out with the students who had taken the General Physics-I course before and with 60 students in their second year of education. The item difficulty $(\mathrm{p})$ and discrimination $(\mathrm{r})$ of the questions were calculated in order to increase the content validity of the PCT. The item difficulty index (p) is the correct answer rate of the item and it can be any value between 0 and 1 , and it can be any value between -1 and +1 of the item discrimination index [51]. As a result of the analyses, the items with a difficulty 
index (p) of 0.82 and 0.85 were removed from the test. Therefore, two questions were removed and the PCT that was formed of 34 multiple choice questions was finalized. The Kuder-Richardson coefficient 20 was calculated as 0.82 for the reliability of the measurements that were obtained from the PCT test, in which the item analysis was carried out. A reality coefficient of above 0.70 indicates that the measurement carried out by the test is reliable [52]. Thus, it has been determined that the PCT that was formed of 30 items was a reliable and valid assessment tool. The PCT that was developed was used as a pre-test before the implementation in order to determine whether the experiment and control group students' conceptual knowledge was equal and it was subsequently used as a post-test in order to measure the misconceptions after the experimental process. The PCT includes subjects, such as force-movement, repulsion, power, and linear momentum.

\subsubsection{Problem Solving Inventory (PSI)}

A Problem Solving Inventory (PSI) has been used in this study to determine the effects of physics teaching with $\mathrm{CBCM}$ that was integrated with Google Classroom on students' problem solving skills. A Problem Solving Inventory is a self-assessment scale that measures the self-perception of an individual's problem solving skills. Heppner and Petersen developed the PSI that has been used in the study [53], and it was adapted to Turkish by Sahin, Sahin, and Heppner [54]. PSI is an assessment tool that is formed of 32 items and a six-point Likert scale $(1=$ never, $2=$ rarely, $3=$ sometimes, $4=$ often, $5=$ usually, $6=$ always) and the Cronbach's alpha reliability coefficient of the PSI was calculated as 0.88 , while the reliability coefficient was 0.85 . There are six sub-dimensions that are found in the PSI, which are: Impulsive $(13,14,15,17,21,25,26,30,32)$, Reflective $(18,20,31,33$, 35), Problem solving Confidence (5, 23, 24, 27, 28, 34), Avoidant style (1, 2, 3, 4, 11), Monitoring (6, 7, 8), and Planfulness (10, $12,16,19)$. The Cronbach's alpha coefficients of the sub-dimensions are calculated as $0.74,0.73,0.72$, $0.66,0.76$, and 0.69 , respectively. The items that are numbered 9,22 , and 29 have not been included in the calculation. The score range is 32-192. The high level of the total scores on the scale indicates that the individuals perceive themselves as insufficient in problem solving. In short, the problem solving score is inversely proportional to the problem solving skill. PSI was used as a pre-test before the experimental study and as a post-test after the study for the experimental and control group students.

\subsubsection{Semi-Structured Interview}

The researcher developed a semi-structured interview form in order to determine the students' views towards the physics teaching with While preparing the interview questions, the existing studies on computer-based concept maps in the literature were used $[55,56]$ in order to provide content validity. After the interview questions were prepared, they were presented to two educational technology experts and two training program specialists in order to determine the comprehensibility and suitability. The necessary arrangements were made according to the feedback from the four experts to whom the interview questions were presented and then the questions were finalized. The interviews were conducted face to face with 17 volunteer students from the experimental group after the experimental implementation. In order to prevent data loss, the interviews were recorded and then transcribed.

\subsection{Data Analysis}

During the data analysis, as a first step, a test of normality was applied to the experimental and control group of students, namely the Kolmogorov-Smirnov test. Parametric techniques were used because test scores had a normal distribution.

Individual sample $t$-test and ANCOVA were conducted in order to determine whether there was a statistically significant difference between the experimental group and control group regarding physics misconceptions and problem solving skills. An alpha level of 0.05 was used for all statistical tests.

The content analysis method was applied to the qualitative data obtained from the semi-structural interviews that were conducted with the experimental group. The interviews with each student had 
duration of between four and six minutes and all were recorded. The students' names were marked as $\mathrm{S} 1, \mathrm{~S} 2, \mathrm{~S} 3, \ldots$ in order to follow the ethical guidelines of the research. The appropriateness of the coding in the study was presented to two experts for peer review. Experts agreed on all codes. In order to increase the reliability of the study, some of the data that were obtained were presented using the direct citation method to present student opinions.

\section{Results}

A pre-test on Physics concepts and Problem Solving Inventory was conducted before the four-week teaching experiment began, and when the experiment had been completed, a post-test was done on Physics Conceptions and Problem Solving Inventory. Semi-structured interviews were also conducted with the experimental group.

\subsection{Physics Conceptions}

Before the start of the learning activities, the PCT was applied as a pre-test to determine whether the experimental and control groups were equal regarding their physics misconceptions. Based on the PCT pre-test results of the experimental and control groups, an independent sample $t$-test was conducted (Table 1).

Table 1. The pre-test of Physics Concept Test (PCT).

\begin{tabular}{cccccc}
\hline Group & $\mathbf{N}$ & Mean & SD & $t$ & $p$ \\
\hline Experiment & 33 & 9.97 & 5.07 & 1.201 & 0.234 \\
Control & 32 & 8.56 & 4.33 & & \\
\hline \multicolumn{5}{c}{ Significant at the 0.05 level. }
\end{tabular}

The statistical results revealed that the results of the physics conceptions pre-test did not significantly differ between the control and the experiment groups $(t=1.201, p>0.05)$.

This finding indicates that the experimental and control groups were equal regarding physics conceptions information before the experimental implementation. In the study, PCY was applied as a post-test in order to determine whether there were any changes in the level of physics misconceptions of the experimental and control groups after the experimental process had been completed (after four weeks). An independent sample $t$-test was conducted on the PCT post-test results of the experimental and control groups (Table 2).

Table 2. The post-test of PCT.

\begin{tabular}{cccccc}
\hline Group & $\mathbf{N}$ & Mean & SD & $\boldsymbol{t}$ & $\boldsymbol{P}$ \\
\hline Experiment & 33 & 14.06 & 6.00 & 2.245 & 0.028 \\
Control & 32 & 11.00 & 4.92 & & \\
\hline \multicolumn{6}{c}{ Significant at the 0.05 level. }
\end{tabular}

The statistical results revealed that the results of the physics conceptions post-test significantly differed between the control and the experiment groups $(t=2.245, p<0.05)$. According to this result, it can be concluded that the teaching in the CBCM environment integrated to Google Classroom can reduce the students' misconceptions and provide meaningful learning.

\subsection{Problem Solving Skills}

ANCOVA was used in this study to examine the effect of the CBCM learning environment that was integrated into Google Classroom on the students' problem solving skills. The pre-test scores were taken as covariate, while the post-test scores were taken as dependent variables. The normality test, namely the Kolmogorov-Smirnov test, was applied to the data that were obtained from PSI, and it has been found that they exhibited a normal distribution. After the hypothesis of normality, 
the homogeneity of group variances was checked by the Levene test and no statistically significant difference was observed $(p>0.05)$. Descriptive statistics of the PSI pre-test and PSI post-test scores that were applied to the experimental and control groups are presented in Table 3.

Table 3. The descriptive statistics for scores of the Problem Solving Inventory (PSI).

\begin{tabular}{ccccccc}
\hline \multirow{2}{*}{ Dimension } & \multirow{2}{*}{ Group } & \multirow{2}{*}{} & \multicolumn{2}{c}{ Pre-Test } & \multicolumn{2}{c}{ Post-Test } \\
\cline { 4 - 7 } & & Mean & SD & Mean & SD \\
\hline \multirow{2}{*}{ Impulsive style } & Experiment & 33 & 17.58 & 3.49 & 10.70 & 3.68 \\
& Control & 32 & 17.94 & 3.27 & 17.84 & 4.75 \\
\hline \multirow{2}{*}{ Reflective style } & Experiment & 33 & 11.64 & 2.07 & 14.18 & 3.58 \\
& Control & 32 & 11.59 & 2.03 & 11.63 & 2.30 \\
\hline \multirow{2}{*}{ Problem solving } & Experiment & 33 & 12.70 & 2.78 & 12.73 & 2.57 \\
confidence & Control & 32 & 12.59 & 2.54 & 12.72 & 3.09 \\
\hline \multirow{2}{*}{ Avoidant style } & Experiment & 33 & 8.91 & 2.36 & 5.36 & 1.90 \\
& Control & 32 & 10.00 & 2.94 & 10.06 & 3.37 \\
\hline \multirow{2}{*}{ Monitoring } & Experiment & 33 & 6.79 & 2.10 & 7.00 & 2.51 \\
& Control & 32 & 6.19 & 2.12 & 6.28 & 2.48 \\
\hline \multirow{2}{*}{ Planfulness } & Experiment & 33 & 8.64 & 2.43 & 8.70 & 2.44 \\
& Control & 32 & 8.78 & 2.21 & 8.72 & 2.44 \\
\hline \multirow{2}{*}{ Total } & Experiment & 33 & 66.24 & 9.31 & 58.67 & 10.92 \\
& Control & 32 & 67.09 & 7.40 & 67.25 & 8.34 \\
\hline
\end{tabular}

The adjusted means of the pre-test were determined so that the PSI post-test scores of the students of the experimental and control groups could be compared. The average post-test means and the adjusted means of the groups are presented in Table 4 for comparison.

Table 4. PSI post-test means and the adjusted means.

\begin{tabular}{ccccc}
\hline Dimension & Group & $\mathbf{N}$ & Mean & Adjusted Mean \\
\hline \multirow{2}{*}{ Impulsive style } & Experiment & 33 & 10.70 & 10.87 \\
& Control & 32 & 17.84 & 17.67 \\
\hline \multirow{2}{*}{ Reflective style } & Experiment & 33 & 14.18 & 14.16 \\
& Control & 32 & 11.63 & 11.65 \\
\hline \multirow{2}{*}{ Problem solving } & Experiment & 33 & 12.73 & 12.69 \\
confidence & Control & 32 & 12.72 & 12.76 \\
\hline \multirow{2}{*}{ Avoidant style } & Experiment & 33 & 5.36 & 5.83 \\
& Control & 32 & 10.06 & 9.58 \\
\hline \multirow{2}{*}{ Monitoring } & Experiment & 33 & 7.00 & 6.68 \\
& Control & 32 & 6.28 & 6.62 \\
\hline \multirow{2}{*}{ Planfulness } & Experiment & 33 & 8.70 & 8.76 \\
& Control & 32 & 8.72 & 8.65 \\
\hline
\end{tabular}

The results of the ANCOVA test, indicating whether the difference between the adjusted means of the post-test of the groups was significant, have been presented in Table 5. 
Table 5. Results of Covariance Analysis of PSI post-test averages of the Experimental and Control Groups.

\begin{tabular}{|c|c|c|c|c|c|c|}
\hline Source of Variance & Dimension & $\begin{array}{l}\text { Sum of } \\
\text { Squares }\end{array}$ & SD & $\begin{array}{l}\text { Mean of } \\
\text { Squares }\end{array}$ & $\mathbf{F}$ & $p$ \\
\hline Controlled variable (PSI pre-test) & \multirow{4}{*}{$\begin{array}{l}\text { Impulsive } \\
\text { style }\end{array}$} & 681.536 & 1 & 681.536 & 93.973 & 0.000 \\
\hline Group & & 747.983 & 1 & 747.983 & 103.135 & 0.000 \\
\hline Error & & 449.652 & 62 & 7.252 & & \\
\hline Total & & $15,096.000$ & 65 & & & \\
\hline Controlled variable (PSI pre-test) & \multirow{4}{*}{$\begin{array}{l}\text { Reflective } \\
\text { style }\end{array}$} & 374.662 & 1 & 374.662 & 116.292 & 0.000 \\
\hline Group & & 102.030 & 1 & 102.030 & 31.669 & 0.000 \\
\hline Error & & 199.747 & 62 & 3.222 & & \\
\hline Total & & $11,536.000$ & 65 & & & \\
\hline Controlled variable (PSI pre-test) & \multirow{4}{*}{$\begin{array}{c}\text { Problem } \\
\text { solving } \\
\text { confidence }\end{array}$} & 305.843 & 1 & 305.843 & 93.331 & 0.000 \\
\hline Group & & 0.096 & 1 & 0.096 & 0.029 & 0.865 \\
\hline Error & & 203.172 & 62 & 3.277 & & \\
\hline Total & & $11,031.000$ & 65 & & & \\
\hline Controlled variable (PSI pre-test) & \multirow{4}{*}{$\begin{array}{l}\text { Avoidant } \\
\text { Style }\end{array}$} & 333.685 & 1 & 333.685 & 154.592 & 0.000 \\
\hline Group & & 219.689 & 1 & 219.689 & 101.779 & 0.000 \\
\hline Error & & 133.826 & 62 & 2.158 & & \\
\hline Total & & 4657.000 & 65 & & & \\
\hline Controlled variable (PSI pre-test) & \multirow{4}{*}{ Monitoring } & 339.015 & 1 & 339.015 & 393.221 & 0.000 \\
\hline Group & & 0.055 & 1 & 0.055 & 0.63 & 0.802 \\
\hline Error & & 53.453 & 62 & 0.862 & & \\
\hline Total & & 3272.000 & 65 & & & \\
\hline Controlled variable (PSI pre-test) & \multirow{4}{*}{ Planfulness } & 264.543 & 1 & 264.543 & 147.903 & 0.000 \\
\hline Group & & 0.182 & 1 & 0.182 & 0.102 & 0.751 \\
\hline Error & & 110.895 & 62 & 1.789 & & \\
\hline Total & & 5304.000 & 65 & & & \\
\hline
\end{tabular}

According to Table 5, the results for the experimental and the control groups showed that there was a significant difference between the adjusted post-test means of the groups when the PSI's pre-test scores of the "Impulsive style" $\left(\mathrm{F}_{(1,62)}=103.135, p<0.05\right)$ and "Avoidant style" $\left(\mathrm{F}_{(1,62)}=101.779\right.$, $p<0.05)$ dimensions were taken under control. The calculated eta-squared values for the determination of the effect size of this difference were found to be $\left(\eta^{2}\right) 0.602$ and $\left(\eta^{2}\right) 0.714$, respectively. As these values are greater than 0.14 , this shows that the power of the effect is high.

According to these results, there was a significant decrease in the scores for the impulsive style and avoidant style dimensions in the experimental group as compared to the control group. In other words, it can be said that teaching in the CBCM environment integrated into Google Classroom is an effective way of reducing students' impulsive and avoidant approaches when solving problems.

It has been determined that there was no significant difference between the groups' adjusted post-test means when the PSI's "Problem solving confidence" $\left(\mathrm{F}_{(1,62)}=0.029, p<0.05\right)$, "Monitoring" $\left(\mathrm{F}_{(1,62)}=0.63, p<0.05\right)$, and "Planfulness" $\left(\mathrm{F}_{(1,62)}=0.102, p<0.05\right)$ dimensions' pre-test scores were taken under control. In other words, it can be said that the students who are being taught with CBCM do not have any influence on their problem solving confidence. A significant difference was found between the adjusted post-test means of the groups $\left(\mathrm{F}_{(1,62)}=31.669, p<0.05\right)$ when the pre-test scores of the PSI's "Reflective style" dimension were controlled. The calculated value of eta squared $\left(\eta^{2}\right)$ was 0.652 , which indicates the effect size of this difference. If this value is greater than 0.14 , it indicates that the power of influence is high. According to this result, the scores of the experimental group in the "Reflective style" dimension significantly increased when compared to the control group. Based on this finding, it can be said that teaching with $\mathrm{CBCM}$ that is integrated into Google Classroom has a positive effect in improving the reflective style of students while solving problems. 


\subsection{Students' Perceptions}

Semi-structured interviews were conducted with 17 volunteer students in the experimental group to determine their perceptions towards teaching in the $\mathrm{CBCM}$ environment integrated with the Google Classroom. The first question asked what the benefits of teaching in this environment were. The second question was about the problems in this environment and the third question was about the suggestions of the students for tackling these problems. The codings that were obtained after examining the qualitative data gathered from the students' answers and the frequencies of these codings have been presented in Table 6.

Table 6. Students' perceptions of the computer-based concept mapping (CBCM) environment integrated with Google Classroom.

\begin{tabular}{ccc}
\hline \multirow{2}{*}{ Context } & Code & Frequency \\
\hline \multirow{3}{*}{ Benefits } & Enhanced sustainability of problem solving activities. & 16 \\
\cline { 2 - 3 } & Enhanced sustainability in learning & 14 \\
\cline { 2 - 3 } & $\begin{array}{c}\text { Enabling the correction of the old concepts that have } \\
\text { been learned incorrectly }\end{array}$ & 13 \\
\cline { 2 - 3 } & Providing a link between prior and new information & 10 \\
\cline { 2 - 3 } & Making problem solving entertaining & 7 \\
\cline { 2 - 3 } Difficulties & Increasing self-confidence towards the course. & 7 \\
\cline { 2 - 3 } & I did not experience any difficulty. & 13 \\
\cline { 2 - 3 } & Difficulty in learning the MindMup application & 3 \\
\hline \multirow{2}{*}{ Solution Recommendations } & Not having previous experience in concept mapping & 3 \\
\hline & $\begin{array}{c}\text { Being trained for the use of MindMup application for } \\
\text { a longer time }\end{array}$ & 4 \\
\hline
\end{tabular}

According to the codes under the context of the benefits of the environment, the majority of the students $(\mathrm{f}=16)$ indicated that teaching with $\mathrm{CBCM}$ enhanced the sustainability of problem solving activities. Some of the students $(\mathrm{f}=14)$ stated that it enhanced sustainability in meaningful learning, while some of them $(f=13)$ stated that it enables the correction of old concepts that have been incorrectly learned.

Similarly, a majority of the participants $(\mathrm{f}=10)$ emphasized that $\mathrm{CBCM}$ provides a link between prior and new information. The students $(\mathrm{f}=7)$ stated that it provides meaningful learning by embodying abstract concepts and they also stated $(f=7)$ that it increases their self-confidence towards the course. Some examples from the students' statements are, as follows:

"It has enabled me to link my prior knowledge and new knowledge. Thus, more meaningful learning has occurred." (S11)

"I always memorized information in physics classes. I did not know what the concepts actually meant. I used to solve problems by placing the variables into the formulas. I can understand the concepts with this approach." (S4)

"I found out that some of the physics information that I learned in high school was wrong. Therefore, I corrected my wrong knowledge." (S9)

It has been revealed from the codings that are related to the context of difficulties experienced in the environment that the majority of the students $(f=13)$ did not experience any difficulties in the environment. Some of the students $(f=4)$ indicated that they experienced difficulties in learning the MindMup application, while some of them $(f=3)$ indicated that they experienced difficulties, because they had never used a concept map before. When the students were asked about recommendations for 
solutions on the difficulties that are experienced in the CBCM environment integrated with Google Classroom, some students $(f=4)$ stated that they needed to be trained in the use of MindMup application for a longer time.

\section{Discussion and Conclusions}

In this study, the impact of the CBCM environment integrated with Google Classroom on students' existing misconceptions, ability to learn new concepts correctly, and problem solving skills have been investigated. Furthermore, the study examined the effect of $\mathrm{CBCM}$ on the sustainability of concept teaching according to student views.

The research results have shown that the CBCM integrated with Google Classroom has enabled the students to learn correctly by adjusting their misconceptions. We believe that result is because every week the instructor prepared and shared Concept Map-A in advance with the students through Google Classroom Concept Map-A. Resultantly, the students had the opportunity to review the old concepts and test their knowledge.

Furthermore, instant feedback to the Concept Map-B in the classroom environment may have prevented the misconceptions. In a similar study [20], it was stated that providing instant feedback in concept learning had a significant effect on the meaningful learning of difficult concepts. Furthermore, the opportunity for direct access to the information sources contributes to the visualization and analysis of the abstract concepts and events on the concept maps that were created in the computer environment. For instance, if the users do not understand a concept on the computer-based concept mapping, they can access the information explaining the concept by clicking on the map with the mouse. This result of the study is in line with studies that have determined that concept maps are effective in eliminating misconceptions [57,58].

According to another result of this study, teaching in the CBCM environment has revealed that the impulse and avoidance tendencies of the students in problem solving have decreased, while their reflective style has increased. It is believed that having discussions regarding concept maps during the concept learning affects the realization of the thinking activities. In support of this finding of the study, Kinchin stated that discussing the concept maps enables students to think about the points that they did not understand before [59]. Furthermore, it has been stated that the concept maps are effective techniques in initiating the thinking process in problem solving, facilitating the correct definition of problem solving, and directing students to alternative problem solving methods [22]. Elias and Weissberg emphasized the importance of an effective thinking activity in every stage of problem solving in order for the individual to be able to realize successful problem solving activities [60]. On the other hand, it is believed that giving individual feedback to the students regarding their concept maps and problem solving on the Google Classroom has a positive effect on their problem solving skills. In support of this finding, Demirel and Karakus Yilmaz emphasized in their studies that feedback and activities were important factors in improving the students' problem solving skills [61].

It has been revealed that teaching with $\mathrm{CBCM}$ did not have any effect on the students' problem solving confidence and their tendencies to be evaluative and organized. It is believed that the reason for this result was due to the fact that $\mathrm{CBCM}$ teaching was carried out only for a period of four weeks. According to another result of the research, the students indicated that teaching with $\mathrm{CBCM}$ enhanced the sustainability of problem solving activities.

On the other hand, when the students' views towards CBCM integrated with Google Classroom have been analysed, it has been revealed that the students stated that their problem solving performance increased and that they enjoyed the problem solving processes. It is believed that visualizing their thoughts during the problem solving process on the MindMup application had an effect on this result. In addition, the students stated that there was a decrease in their misconceptions. Furthermore, the students also stated that using this application did not cause any difficulties for them. This result is thought to be because the MindMup application is easy to use. Additionally, the students stated that CBCM enhanced sustainability in meaningful learning. 
This study has shown that the Google Classroom and computer-based concept mapping techniques can be used together in harmony. Furthermore, the results of this study point toward the importance of supporting a pedagogical and technical environment for technology enhanced learning. Similarly, Varouchas, Sicilia, and Sánchez-Alonso stated that technology-enhanced learning is as a key quality driver in higher education [62]. Zhuhadar, Yang, and Lytras, in their research, concluded that the Social Multimedia System makes an important contribution to learning and achievement [63].

\section{Limitations and Future Research}

This research, as with any other empirical study, has limitations. Firstly, the participants of this study were only formed of students who were studying in a private university in North Cyprus. Thus, the results cannot be nationally generalized. The study can be conducted with students from different universities and with more participants. Secondly, in order to obtain more detailed information, more questions could have been asked in the semi-structural interviews that were carried out with the experimental group. Asking only three questions has reduced the amount of data in the qualitative dimension of the study. In future studies, more detailed questions can be asked to the students regarding the environment. The third limitation of the study was that the experimental process was only four weeks. In future studies, the experimental process could be longer and the impact on the learning outcomes can be analysed. The final limitation of the study was that separate classes were created in Google Classroom, namely the experimental and control group, in order to prevent student interactions during the distant learning processes. However, the interaction among the members of the groups was not analysed. This situation is a limitation of the study. These student interactions can be analysed in further studies.

Future research should shed light on technology enhanced learning area, not only from the perspective of learning outcomes of use of computer-based concept map. In the current study, the concept maps were pre-created and then shared by the instructor. The students filled in the missing parts of the concept maps. However, in order to develop technical knowledge and usage skills, students should create their maps themselves using different digital concept map applications and tools in further studies. For students, academic results are only one part of the technology enhanced learning environment, as the work with digital technologies increases participation in courses and interest in learning. In addition, it is important to understand how the advances in information and communication technologies are effectively employed in the field of education [64].

Smart cities present a strong technological component. In Technology Enhanced Learning, the role of technology is to facilitate the acquisition of higher-order skills. Current research that is implemented to learn in the cities has focused on two main technological means for learning contents: applications and mobile devices. The present study focused on the learning applications.

Funding: This research received no external funding.

Acknowledgments: The author wishes to thank the participating respondents for their time and effort.

Conflicts of Interest: The author declares no conflict of interest.

\section{References}

1. Watson, M.K.; Pelkey, J.; Noyes, C.R.; Rodgers, M.O. Use of Concept Maps to Assess Student Sustainability Knowledge. In Proceedings of the American Society for Engineering Education Annual Conference and Exposition, Indianapolis, IN, USA, 15-18 June 2014.

2. Hansmann, R.; Hansmann, R. "Sustainability Learning": An Introduction to the Concept and Its Motivational Aspects. Sustainability 2010, 2, 2873-2897. [CrossRef]

3. Daniela, L.; Visvizi, A.; Gutiérrez-Braojos, C.; Lytras, M.D. Sustainable Higher Education and Technology-Enhanced Learning (TEL). Sustainability 2018, 10, 3883. [CrossRef]

4. Riche, R.D. Strategies for Assisting Students to Overcome Their Misconceptions in High School Physics; Memorial University of Newfoundland Education: St. John's, NL, Canada, 2000; p. 6390. 
5. Ormrod, J.E. Educational Psychology, Developing Learners, 4th ed.; Merrill Prentice Hall: Upper Saddle River, NJ, USA, 2003.

6. Sadanand, N.; Kess, J. Concepts in force and motion. Phys. Teach. 1990, 28, 530-533. [CrossRef]

7. Wang, M.; Wu, B.; Kirschner, P.A.; Spector, J.M. Using cognitive mapping to foster deeper learning with complex problems in a computer-based environment. Comput. Hum. Behav. 2018, 87, 450-458. [CrossRef]

8. Novak, J.D.; Musonda, D. A Twelve-Year Longitudinal Study of Science Concept Learning. Am. Educ. Res. J. 1991, 28, 117-153. [CrossRef]

9. Novak, J.; Gowin, B. Learning How to Learn; Cambridge University Press: New York, NY, USA, 1984.

10. Ausubel, D.P. The Psychology of Meaningful Verbal Learning; Grune \& Stratton: New York, NY, USA, 1963.

11. Novak, J.D. Learning, Creating, and Using Knowledge: Concept Maps as Facilitative Tools in Schools and Corporations, 2nd ed.; Routledge: Abingdon, UK, 2010.

12. Visvizi, A.; Lytras, M.; Daniela, L. Education, innovation and the prospect of sustainable growth and development. In The Future of Innovation and Technology in Education: Policies and Practices for Teaching and Learning Excellence; Visvizi, A., Lytras, M., Daniela, L., Eds.; Emerald Publishing: Bingley, UK, 2018.

13. Chang, K.E.; Yao-Ting, S.; Rey-Bin, C.; Shui-Cheng, L. A new assessment for computer-based concept mapping. J. Educ. Technol. Soc. 2005, 8, 138-148.

14. Rautama, E. Extending the Delivery of Concept Maps. In Proceedings of the AAPS Project, ITiCSE2000, The 5th Annual Conference on Innovation and Technology in Computer Science Education, Helsinki, Finland, 11-13 July 2000.

15. Shute, V.J.; Jeong, A.C.; Spector, J.M.; Seel, N.M.; Johnson, T.E. Model-based methods for assessment, learning and instruction: Innovative educational technology at Florida state university. In Educational Media and Technology Yearbook; Springer: Boston, MA, USA, 2009; pp. 61-79.

16. Gijlers, H.; de Jong, T. Using concept maps to facilitate collaborative simulation-based inquiry learning. J. Learn. Sci. 2013, 22, 340-374. [CrossRef]

17. Hwang, G.J.; Kuo, F.R.; Chen, N.S.; Ho, H.J. Effects of an integrated concept mapping and web-based problem-solving approach on students' learning achievements, perceptions and cognitive loads. Comput. Educ. 2014, 71, 77-86. [CrossRef]

18. Jonassen, D.H. Learning to Solve Problems. An Instructional Design Guide; John Wiley \& Sons: San Francisco, CA, USA, 2004.

19. Denton, P.; Madden, J.; Roberts, M.; Rowe, P. Students' response to traditional and computer-assisted formative feedback: a comparative case study. Brit. J. Educ. Technol. 2008, 39, 486-500. [CrossRef]

20. Wu, P.H.; Hwang, G.J.; Milrad, M.; Ke, H.R.; Huang, Y.M. An innovative concept map approach for improving students' learning performance with an instant feedback mechanism. Brit. J. Educ. Technol. 2012, 43, $217-232$. [CrossRef]

21. Lin, Y.T.; Chang, C.H.; Hou, H.T.; Wu, K.C. Exploring the effects of employing Google Docs in collaborative concept mapping on achievement, concept representation, and attitudes. Interact. Learn. Environ. 2015, 24, 1-22. [CrossRef]

22. Harini, L.P.I.; Nilakusmawati, D.P.; Astawa, I.G.S. Solve Miscellaneous Mathematical Problems using Mind Map. Global J. Pure Appl. Math. 2017, 13, 7441-7451.

23. Hwang, G.J.; Chen, M.R.A.; Sung, H.Y.; Lin, M.H. Effects of integrating a concept mapping-based summarization strategy into flipped learning on students' reading performances and perceptions in Chinese courses. Br. J. Educ. Technol. 2018. [CrossRef]

24. Ruiz-Primo, M.A.; Schultz, S.E.; Li, M.; Shavelson, R.J. Comparison of the reliability and validity of scores from two concept-mapping techniques. J. Res. Sci. Teach. 2001, 38, 260-278. [CrossRef]

25. Moon, B.; Hoffman, R.R.; Novak, J.; Canas, A. (Eds.) Applied Concept Mapping: Capturing, Analyzing, and Organizing Knowledge; CRC Press: Boca Raton, FL, USA, 2011.

26. Dosanjh, N.K. The Effects of Three Concept Mapping Strategies on Seventh-Grade Students' Science Achievement at An Urban Middle School. Ph.D. Thesis, The University of San Francisco, San Francisco, CA, USA, 2011.

27. Nakipoglu, C.; Ertem, H. Comparison of the Structural, Relational and Proposition Accuracy Scoring Results of Concept Maps about Atom. J. Turk. Sci. Educ. 2010, 7, 60-77. 
28. Akinoglu, O.; Yasar, Z. The Effects of Note-Taking in Science Education Through the Mind Mapping Technique on Students' attitudes, Academic Achievement and Concept Learning. J. Balt. Sci. Educ. 2007, 6, $34-43$.

29. Conradty, C.; Bogner, F.X. Implementation of concept mapping to novices: reasons for errors, a matter of technique or content? Educ. Stud. 2010, 36, 47-58. [CrossRef]

30. Watson, M.K.; Pelkey, J.; Noyes, C.R.; Rodgers, M.O. Assessing conceptual knowledge using three concept map scoring methods. J. Eng. Educ. 2016, 105, 118-146. [CrossRef]

31. Lin, Y.S.; Chang, Y.C.; Liew, K.H.; Chu, C.P. Effects of concept map extraction and a test-based diagnostic environment on learning achievement and learners' perceptions. Br. J. Educ. Technol. 2016, 47, 649-664. [CrossRef]

32. Chang, C.-C.; Liu, G.-Y.; Chen, K.-J.; Huang, C.-H.; Lai, Y.-M.; Yeh, T.-K. The Effects of a Collaborative Computer-based Concept Mapping Strategy on Geographic Science Performance in Junior High School Students. Eurasia J. Math. Sci. Technol. Educ. 2017, 13, 5049-5060. [CrossRef]

33. Mammen, J.R. Computer-assisted concept mapping: Visual aids for knowledge construction. J. Nurs. Educ. 2016, 55, 403-406. [CrossRef] [PubMed]

34. Chiou, C.-C.; Lee, L.-T.; Tien, L.-C.; Wang, Y.-M. Analyzing the Effects of various Concept Mapping Techniques on Learning Achievement under different Learning Styles. Eurasıa J. Math. Sci. Technol. Educ. 2017, 13, 3687-3708. [CrossRef]

35. Plotnick, E. Concept Mapping: A Graphical System for Understanding the Relationship Between Concepts. In ERIC Digest. Available online: https:/ files.eric.ed.gov / fulltext/ED407938.pdf (accessed on 22 July 2018).

36. Liu, P.L.; Chen, C.J.; Chang, Y.J. Effects of a computer-assisted concept mapping learning strategy on EFL college students' English reading comprehension. Comput. Educ. 2010, 54, 436-445. [CrossRef]

37. Hwang, G.J.; Wu, P.H.; Ke, H.R. An interactive concept map approach to supporting mobile learning activities for natural science courses. Comput. Educ. 2011, 57, 2272-2280. [CrossRef]

38. Chu, H.C.; Hwang, G.J.; Liang, Y.R. A cooperative computerized concept-mapping approach to improving students' learning performance in web-based information-seeking activities. J. Comput. Educ. 2014, 1, 19-33. [CrossRef]

39. Shamsuddin, I.M.; Aminu, I.; Shamsiyya, A.; Adamu, A.M. Influence of Computer Assisted Concept Mapping Instructional Strategy on Students Performance in Chemistry. Teach. Educ. Curric. Stud. 2017, 2, 86-92. [CrossRef]

40. Altun, I. The perceived problem-solving ability and values of student nurses and midwives. Nurs. Educ. Today 2003, 23, 575-584. [CrossRef]

41. Wu, T.; Custer, T.L.; Dyrenfurth, M.J. Technological and personal problem-solving styles: Is there a difference? J. Technol. Educ. 1996, 7, 55-71. [CrossRef]

42. Ocak, G.; Eğmir, E. Investigation of pre-service teachers' problem-solving skills in terms of different variables. Asian J. Instruct. 2014, 2, 27-45.

43. Miller, M.; Nunn, G.D. Using group discussion to improve social problem solving and learning. Education 2001, 121, 470-475.

44. Wang, M.; Derry, S.; Ge, X. Guest Editorial: Fostering deep learning in problem-solving contexts with the support of technology. Educ. Technol. Soc. 2017, 20, 162-165.

45. González, H.; Palencia, A.; Umaña, L.; Galindo, L.; Villafrade, L. Mediated learning experience, and concept maps: A pedagogical tool for achieving meaningful learning in medical physiology students. Adv. Physiol. Educ. 2008, 32, 312-316. [CrossRef] [PubMed]

46. Sarker, P. Use of concept maps for problem-solving in engineering. Global J. Eng. Educ. 2015, 17, $29-33$.

47. Keeler, A. 15 More Things You Can Do with Google Classroom. Available online: http:/ /www.alicekeeler.com/ teachertech/2014/09/22/15-more-things-you-can-do-with-google-classroom/ (accessed on 10 June 2018).

48. Shaharanee, I.N.M.; Jamil, J.M.; Rodzi, S.S.M. Google Classroom as A Tool for Active Learning. AIP Conf. Proc. 2016, 1761, 020069. [CrossRef]

49. Iftakhar, S. Google classroom: what works and how? J. Educ. Soc. Sci. 2016, 3, 12-18. Available online: http:/ /jesoc.com/wp-content/uploads/2016/03/KC3_35.pdf (accessed on 29 July 2018).

50. Young, H.D.; Freedman, R.A.; Ford, A.L. Sears and Zemansky's University Physics with Modern Physics, 13th ed.; Pearson Education: San Francisco, CA, USA, 2010.

51. Büyüköztürk, S.. Data Analysis Handbook for Social Sciences, 7th ed.; Pegem A Publishing: Ankara, Turkey, 2007. 
52. Field, A. Discovering Statistics Using SPSS, 3rd ed.; Sage: London, UK, 2009.

53. Heppner, P.P.; Petersen, C.H. The development and implications of a personal problem-solving inventory. J. Couns. Psychol. 1982, 29, 66-75. [CrossRef]

54. Sahin, N.; Sahin, N.H.; Heppner, P.P. Psychometric properties of the problem-solving inventory in a group of Turkish university students. Cogn. Ther. Res. 1993, 17, 379-396. [CrossRef]

55. Balim, A.G. The Effect of Mind-Mapping Applications on Upper Primary Students' Success and Inquiry-Learning Skills in Science and Environment Education. Int. Res. Geogr. Environ. Educ. 2013, 22, 337-352. [CrossRef]

56. Rye, J.; Landenberger, R.; Warner, T.A. Incorporating concept mapping in project-based learning: Lessons from watershed investigations. J. Sci. Educ. Technol. 2013, 22, 379-392. [CrossRef]

57. Engelmann, T.; Hesse, F.W. How digital concept maps about the collaborators' knowledge and information influence computer-supported collaborative problem-solving. Int. J. Comput.-Support. Collab. Learn. 2010, 5, 299-319. [CrossRef]

58. Engelmann, T.; Tergan, S.-O.; Hesse, F.W. Evoking knowledge and information awareness for enhancing computer-supported collaborative problem-solving. J. Exp. Educ. 2010, 78, 1-20. [CrossRef]

59. Kinchin, I.M. Concept Mapping in Biology. J. Biol. Educ. 2000, 34, 61-68. [CrossRef]

60. Elias, M.J.; Weissberg, R.P. Primary prevention: Educational approaches to enhance social and emotional learning. J. Sch. Health. 2000, 70, 186-190. [CrossRef] [PubMed]

61. Demirel, T.; Karakus Yilmaz, T. The Effects of Mind Games in Math and Grammar Courses on The Achievements and Perceived Problem-Solving Skills of Secondary School Students. Available online: https:/ / onlinelibrary.wiley.com/doi/abs/10.1111/bjet.12624 (accessed on 20 October 2018).

62. Varouchas, E.; Sicilia, M.Á.; Sánchez-Alonso, S. Academics' Perceptions on Quality in Higher Education Shaping Key Performance Indicators. Sustainability 2018, 10, 4752. [CrossRef]

63. Zhuhadar, L.; Yang, R.; Lytras, M.D. The impact of Social Multimedia Systems on cyberlearners. Comput. Hum. Behav. 2013, 29, 378-385. [CrossRef]

64. Lytras, M.; Visvizi, A.; Daniela, L.; Sarirete, A.; Ordonez De Pablos, P. Social Networks Research for Sustainable Smart Education. Sustainability 2018, 10, 2974. [CrossRef]

(C) 2019 by the author. Licensee MDPI, Basel, Switzerland. This article is an open access article distributed under the terms and conditions of the Creative Commons Attribution (CC BY) license (http:/ / creativecommons.org/licenses/by/4.0/). 